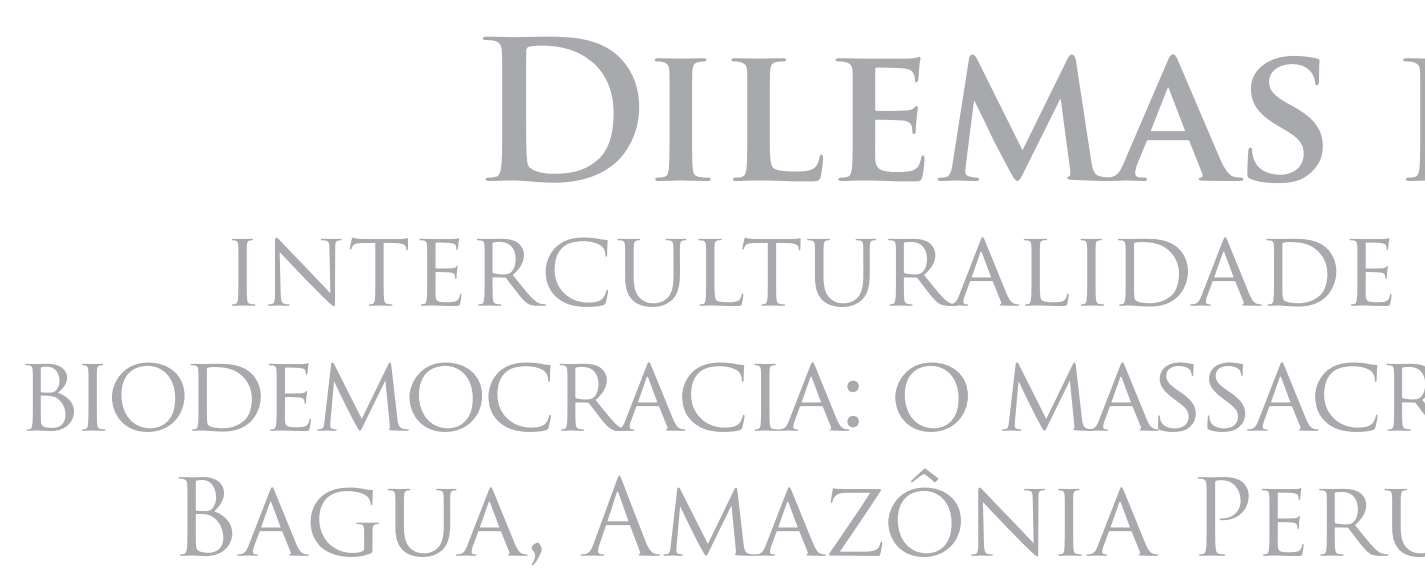




\section{DILEMAS DA INTERCULTURALIDADE E DA BIODEMOCRACIA: O MASSACRE EM BAGUA, AMAZÔNIA PERUANA}

\section{A D R I A N A P A O L A P A R E D E S P E N A F I E L}

UNIVERSIDADE FEDERAL DO RIO GRANDE DO SUL, PORTO ALEGRE, BRASIL

$$
\text { G U I L H E RME RA D OMSKY }
$$




\title{
DILEMAS DA INTERCULTURALIDADE E DA BIODEMOCRACIA: O MASSACRE EM BAGUA, AMAZÔNIA PERUANA
}

\author{
Resumo \\ Neste trabalho, analisamos o massacre ocorrido em junho de 2009 \\ em Bagua, na Amazônia peruana, à luz dos conceitos de intercul- \\ turalidade e biodemocracia. Os conflitos examinados no incidente \\ aparentemente fazem referência unicamente ao problema da dis- \\ puta e do controle de recursos e territórios. No entanto, a finalidade \\ deste texto é mostrar que a exploração da natureza é compreen- \\ dida pelas comunidades indígenas como usurpação dos espaços \\ de vida e desvirtuamento do seu modo de interpretar o mundo. \\ Interculturalidade e biodemocracia, articulados a conceitos como \\ rede, relacionalidade e perspectiva, permitem entendimentos am- \\ pliados sobre o conflito, suas conexões e as (difíceis) resoluções. \\ Palavras-chave: biodemocracia; interculturalidade; Amazônia peruana.
}

\section{DILEMMAS OF THE INTERCULTURALITY AND BIODEMOCRACY: THE MASSACRE IN BAGUA, PERUVIAN AMAZON}

\begin{abstract}
In this paper, we analyze the massacre that occurred in June 2009 in Bagua, Peruvian Amazonia in light of the concepts of interculturality and biodemocracy. Apparently, the examined struggles in the incident only make reference to the problem of the dispute and the control over resources and territories. Nonetheless, the aim of this text is to show that exploitation of natural resources is understood by indigenous communities as the usurpation of their spaces of life and their way to interpret the world. Interculturality and democracy, articulated to concepts such as network, relationality and perspective, allow further understanding about the conflict, their connections and the (difficult) resolutions.
\end{abstract}

Key-words: biodemocracy; interculturality; Peruvian Amazonia. 


\section{DILEMAS DE LA INTERCULTURALIDAD Y DE LA BIODEMOCRACIA: EL MASACRE EN BAGUA, AMAZONÍA PERUANA}

\section{Resúmen}

En este trabajo, analizamos la masacre ocurrida en junio de 2009 en la localidad de Bagua, Amazonía Peruana a la luz de los conceptos de interculturalidad y biodemocracia. Los conflictos examinados en el incidente aparentemente hacen referencia únicamente al problema de la disputa y del control de los recursos y territorios. Sin embargo, la finalidad de este texto es mostrar que la explotación de la naturaleza es comprendida por las comunidades indígenas como usurpación de los espacios de vida y desvirtuamiento de su modo de interpretar el mundo. Interculturalidad y democracia, articulados a los conceptos como red, relacionalidad y perspectiva, permiten entendimientos ampliados sobre el conflicto, sus conexiones y las (difíciles) resoluciones.

Palabras clave: biodemocracia; interculturalidad; Amazonía peruana. 


\section{INTRODUÇÃO}

No dia cinco de junho de 2009, na localidade conhecida como "La Curva del Diablo" (município provincial de Uctubamba-Bagua Grande, Peru), acontece um triste episódio cujas múltiplas versões foram publicadas na mídia nacional e internacional. A polícia nacional peruana e os membros das etnias amazônicas Awajun e Wanpis enfrentam-se provocando a morte de mais de trinta pessoas entre policiais e indígenas, somando mais de cem feridos e um número importante de desaparecidos. Na tarde desse mesmo dia, na estação n. 6 do Oleoduto Norperuano da Petroperú, doze policiais foram vítimas da ira dos manifestantes que, ao saberem do primeiro ataque da polícia, revidaram com violência extrema em razão de entender que a força teria agido sobre população desarmada. $\mathrm{O}$ fato dos indígenas terem sido mortos ganhou pouca veiculação nos meios de comunicação consolidados e tem sido divulgado por canais informais que recuperam depoimentos de residentes de Bagua cujos familiares jamais retornaram para casa e cujos corpos, segundo testemunhas, foram lançados em rios para ocultar evidências.

Esta confrontação ocorreu depois de quase 60 dias de protestos por parte das comunidades indígenas em favor da revogação dos Decretos Legislativos (DL) ditados "excepcionalmente" pelo poder executivo no curto período entre maio e junho de 2008. Os decretos objetivavam a efetivação do Tratado de Livre Comércio (TLC) entre o Peru e os Estados Unidos atendendo a interesses econômicos, principalmente, no território amazônico peruano.

A proliferação de comentários e opiniões após o triste evento, especialmente por parte do governo e das grandes mídias, criou um ambiente em que, direta ou indiretamente, o evento traumático teria origem na ação de algumas pessoas que logo foram consideradas as grandes culpadas: os líderes das comunidades indígenas. Tal discurso se tornou comum e difundido, independente do realmente acontecido. Alberto Pizango, presidente da Associación Interétnica de Desarrollo de la Selva Amazónica (AIDESEP), Cervando Puerta, presidente da Organización Regional de los Pueblos Indígenas de la Amazonía Norte del Perú (ORPIAN), Saul Puerta, secretário da AIDESEP e Teresita Antazú foram denunciados por insurgência e por mobilizar a população contra a ordem pública. No desenrolar dos fatos, dois dias depois do incidente, o governo peruano lança campanhas publicitárias em sua defesa, julgando antecipadamente o episódio. Num dos anúncios, denominou os índios de selvagens e terroristas, além de culpá-los pelas consequências trágicas do evento ${ }^{1}$.

No entanto, o acontecido em Bagua não parece ser um fato isolado. Quase dois meses de mobilização política pelas comunidades indígenas colocam em questão a capacidade do Estado de abrir um espaço de diálogo com populações locais e ter a disposição de entender, ou pelo menos escutar, as suas preocupações. Esse conjunto de 
manifestações que angariam direitos à participação e à formulação de seus projetos coletivos de vida nas comunidades levanta suspeitas acerca dos grandes investimentos, tratados nas grandes mídias e pelas corporações como forma de "um desenvolvimento para todos"; uma estratégia para implementar políticas de estilo "one-size-fits-all" em que os frutos oriundos dos investimentos são apropriados por setores da sociedade. $\mathrm{Na}$ realidade, o que os inúmeros motins e processos (rituais) violentos reforçam é precisamente que os mega-projetos de exploração da natureza são compreendidos pelas comunidades locais como usurpação dos espaços de vida e desvirtuamento do seu modo de interpretar o mundo ${ }^{2}$. Em depoimento, Alberto Pizango, líder indígena, simultaneamente esclarece e desabafa: "somos perseguidos porque nos veem como anti-sistema e o que há é um sistema opressor desde há muitos anos, onde há uma violação dos direitos dos povos indígenas; querem tratar os nativos como vassalos" (Coletivo Indígena 2010: 06). Campos de problemas que sinalizam poderes, direitos e diferenças na interpretação do mundo nos remetem aos dilemas da democracia e, talvez, uma possibilidade crítica construtiva pelo que Escobar (1999) denomina de biodemocracia. Esta "se articula alrededor de una serie de premisas basadas en el control local de los recursos naturales y el apoyo a prácticas fundadas en la lógica de la diversidad" e ainda, segue o autor, "incluyendo el reconocimiento del cimiento cultural de la diversidad biológica" (Escobar 1999: 16-17).
É crucial observar que os desacordos entre comunidades locais, de um lado, e empresas em conjunto com Estados, de outro, têm transcendido dois panoramas: no primeiro, os problemas não são localizados, ainda que sejam os próprios lugares os motivos de conflitos. É o que Tsing (2005) denomina de conexões globais em que mega-projetos movimentam atores individuais $\mathrm{e}$ coletivos além de fronteiras nacionais, fato típico de um mundo de processos econômicos e políticos de escala global. No caso peruano, fazem parte do rol os empresários nacionais e estrangeiros que poderiam transacionar com mais liberdade com a aprovação do TLC, além os acionistas de muitas partes do planeta, as entidades financeiras, entre outros. O segundo, e é isso que gostaríamos de destacar neste artigo, os problemas e eventuais conflitos emergem não como meras disputas sobre quem controla recursos, quais lugares são explorados e quem se apropria dos resultados. Certamente, essa dimensão é central, no entanto ela reduz as relações (de poder ou não) ao campo comum que a ontologia moderna sinaliza como aquele em que se devem realizar os consensos e os conflitos.

Nossa indagação neste artigo, essencialmente, diz respeito a subverter isto por meio dos olhares locais indígenas e dos membros de movimentos sociais, por isso a centralidade de conceitos como biodemocracia e interculturalidade: o que acontece se a base comum sobre a qual consensos e conflitos emergem não é aquela que pensa a razão moderna? Ao contrário, ela in- 
dica uma problematização de um modo de entender a vida, um questionamento sobre o que é este mundo e como devem ocorrer as relações com ele (com a "natureza") e nele (na "sociedade")? Analisando especialmente vultosos projetos de exploração da natureza, qual a possibilidade de ampliarmos o nosso escopo se incluirmos um pensamento diferente, um pensamento que desloca nosso ponto de vista para processos nos quais cultura, sociedade e natureza são entendidos distintamente?

A finalidade do texto é mostrar a diferença de mundos e os modos de viver e como isto possui profunda relação com o massacre em Bagua. Este fundamento é o problema da disputa, pois antes que se torne pelos porta-vozes das grandes corporações e dos Estados simplesmente conflito por recursos, a luta é sobre o que o mundo é e as relações entre o que denominamos sociedade e natureza. No artigo, utilizamos materiais bibliográficos e casos paralelos oriundos da Melanésia, do Brasil e do próprio Peru com o intuito de salientar que as diferentes conexões globais são, em parte, o que Strathern (2004) intitula de conexões parciais: elas estabelecem um circuito de ligações que estabiliza um discurso e permite a apreensão de um determinado problema, mas não deixam de serem parciais, representando multiplicidades de posições não-fechadas.

Do ponto de vista dos procedimentos metodológicos, o trabalho utiliza dados secundários que fornecem um panorama dos acontecimentos analisados: entrevistas de pessoas-chave (lideranças de comunidades e do presidente Alan García) em periódicos e disponíveis em vídeo, compilações a respeito de fatos, dados veiculados em mídias locais (El Comércio e La República) e canais independentes, bem como decretos legislativos relacionados ao incidente e artigos escritos por García e as respostas dos líderes comunitários.

O trabalho está organizado em seis partes, iniciando por esta introdução. $\mathrm{Na}$ segunda parte, descrevemos e examinamos os eventos ocorridos antes do massacre em Bagua e quais discursos alimentaram o desejo de setores da sociedade em direção à exploração das terras amazônicas. $\mathrm{Na}$ terceira, analisamos os decretos legislativos que favoreceram empresas e investimentos nas terras florestais, as respostas dos grupos indígenas e o que estipula a Convenção 169 da Organização Internacional do Trabalho (OIT). Na quarta parte, examinamos em detalhe o confronto e as justificativas em ambos os lados. Na quinta, procuramos embasar a análise na discussão teórica sobre o que são os seres que comumente denominamos de "naturais" ou de "recursos" sob a ótica indígena, enfatizando um conjunto de etnografias sobre o tema. $\mathrm{Na}$ sexta e última parte, traçamos algumas conclusões.

\section{UMA "RECEITA" PARA ATINGIR A MODERNIDADE: TLC CONTRA EL PERRO DEL HORTELANO ${ }^{3}$}

Este tratado [TLC] nos lleva a la modernidad en infinidad de temas, en propiedad intelectual, en medio 
ambiente (Ex-Ministra de Comércio Exterior e Turismo do Peru, Mercedes Aráoz).

El verdadero desarrollo es el que respeta la naturaleza y no violenta sus sistemas [...] Desarrollo no es destrucción. No hay que oprimir a muchos para desarrollar (Presidente da AIDESEP, Alberto Pizango).

O Tratado de Livre Comércio entre Peru e Estados Unidos começou a ser negociado em maio de 2004 durante o governo dos presidentes Alejandro Toledo (2002-2005) e George W. Bush, com vistas a prolongar e aprimorar a anterior Lei de Promoção Comercial Andina e Erradicação de Drogas (APTDEA) que deixaria de vigorar em dezembro de 2002. Com o triunfo eleitoral do atual presidente peruano Alan García Pérez, o TLC foi significativamente almejado e pode-se afirmar que foi considerado uma das grandes bandeiras do governo. Desse ponto de vista, não é difícil perceber que a ênfase da política econômica propõe uma espécie de desenvolvimento nacional em que o mercado tem grande papel para alavancar o crescimento econômico, especialmente apostando nas vultosas cifras que o comércio internacional pode proporcionar. $\mathrm{Na}$ reunião entre os dois mandatários, ocorrida no mês de abril de 2007 em Washington D.C., transcrita e veiculada no portal da Casa Branca, as palavras do Presidente García Perez são bastante evidentes:

Pero este crecimiento, tanto como el desarrollo, necesita de un gran espacio y grado de inversión, y para ese cometido es esencial un TLC. Éste nos ayudará a mantener una democracia firme, una democracia que se ocupe de los más necesitados y que provea de trabajo a los desempleados. Es importante demostrar al mundo que una democracia con inversión nos lleva al desarrollo. Y el desarrollo no se consigue sin hacer nada y sin abrir nuestras puertas al mercado.

Depois de intensas negociações - excluindo, obviamente, grande parcela dos interessados no resultado do acordo - e de debates nacionais, o TLC foi finalmente assinado em dezembro de 2005 por Alan García e George W. Bush, sendo finalmente ratificado por ambos os países no ano de 2007. Nesse ínterim, o presidente García, provavelmente desejando preparar a população sobre os prósperos investimentos que supostamente fluiriam após sua "mágica" assinatura, expôs a sua própria visão sobre o que é o desenvolvimento por meio da publicação de três artigos no jornal de maior circulação do país, El Comercio. Os artigos possuem títulos bastante curiosos e provocadores, interpelam a população a tomar partido e supõem, por sua própria natureza maniqueísta, rachaduras no espaço social que devem ser resolvidas por uma maioria ou por setores da sociedade que enxerga o Peru como uma nação cujo futuro espelhará as escolhas do presente, opções estas que parecem impossíveis de serem postergadas, aos olhos do autor dos artigos. Não é preciso grande astúcia para observar que os textos "El Síndrome del Perro Hortelano" (2007a), "Receta para acabar con el perro del hortelano" (2007b) e "El perro hortelano contra el pobre" 
(2008) causaram um profundo desgosto no seio de comunidades tradicionais indígenas, especialmente da Amazônia.

$\mathrm{Na}$ análise dos escritos do presidente, torna-se claro que aquele que protesta em favor de seus direitos e da preservação do território em que vive é o "perro del hortelano", que simultaneamente condena a si mesmo e aos demais à pobreza. Citamse alguns parágrafos dos escritos que ecoaram profundamente no Peru.

Hay millones de hectáreas para madera que están ociosas, otros millones de hectáreas que las comunidades y asociaciones no han cultivado ni cultivarán, además cientos de depósitos minerales que no se pueden trabajar y millones de hectáreas de mar a los que no entran jamás la maricultura ni la producción. [...] El primer recurso es la Amazonía. Tiene 63 millones de hectáreas y lluvia abundante. En ella, se puede hacer forestación maderera especialmente en los 8 millones de hectáreas destruidas, pero para eso se necesita propiedad, es decir un terreno seguro sobre 5.000, 10.000 o 20.000 hectáreas, pues en menos terreno no hay inversión formal de largo plazo y de alta tecnología. Ahora solo existen las concesiones que dependen de la voluntad del Gobierno y del funcionario que puede modificarlas (García Pérez 2007a: A4).

Cambiar la actitud ante la inversión. Si el Estado quiere promover la inversión privada no puede tener como objetivo que el privado gane lo menos posible, exigiendo condiciones con las que finalmente ningún pos- tor se presenta a los concursos. Por evitar que el inversionista gane 5\% más, nadie viene. En vez de exigir criterios exagerados, debe dejarse al mercado y a la competencia de los privados la fijación de esas condiciones. [...] Recuerde el perro del hortelano la enseñanza de Lenin en su texto "Capitalismo de Estado e impuesto en especie": "Deben venir los capitalistas, ganarán mucho, pero nos enseñarán el camino de la técnica y el desarrollo". Fue un cambio de rumbo genial, pero Lenin murió poco después. Hoy, el perro del hortelano se entusiasma a sí mismo gritando "ni un paso atrás" y se olvida del mismo Lenin que aconsejó: "Un paso atrás para dar dos adelante” (García Pérez 2007b: A6).

Ahora que la batalla ya no es económica porque el mundo aplastó en ese tema al perro del hortelano, este se presenta como antiminero pluriculturalista y patriotero. Dice: "Que los terrenos eriazos se queden como están, que la riqueza forestal de la Amazonía no se aproveche, que no se construyan hoteles cerca de los monumentos arqueológicos". No sabe que en la Torre Eiffel, siendo el mayor atractivo de París, existen desde su origen los restaurantes privados que son los que más recursos dan a ese monumento al cual, por cierto, suben 8 millones de personas anualmente, mientras aquí el perro del hortelano discute si Machu Picchu puede recibir más de 500.000 personas por año. Tampoco sabe que en las pirámides, en el coliseo romano o en los palacios mayas de Chichén Itzá, hay hoteles y lugares de restauración (García Pérez 2008: A4.) 
A importância política e interpelativa dos textos e o clamor para um Peru que explore expressivamente "tesouros" da floresta, mar e subsolo justificam as longas passagens aqui citadas. Efetivamente, não foi surpresa que comunidades tradicionais e especialmente organizações indígenas, como a AIDESEP (organização que representa 1.350 comunidades indígenas em todo o Peru, aproximadamente $350 \mathrm{mil}$ pessoas) mostraram-se ofendidos com o tom depreciativo dos três artigos. Através de uma carta aberta, também disponível na Internet, a AIDESEP responde ao presidente manifestado não apenas uma posição política oposta, mas uma filosofia de vida coletiva em que cultura e natureza não aparecem como termos antitéticos:

[...] Es cierto que existen millones de hectáreas de bosque, pero no todo es madera comerciable. Señor Presidente permítanos aclararle que para obtener la madera que tanto Ud. señala que traería trabajo y recursos al País, es necesario talar muchos árboles de especies no utilizables para fines maderables, y que sin embargo esos árboles son lo que en realidad proveen de oxígeno con el que cuenta el planeta y no solamente los "no conectados" " como Ud. equivocadamente se refiere a nuestros hermanos indígenas no conectados o en aislamiento voluntario. [...] Allí hay ecosistemas en los que el bosque se interrelaciona con las personas que lo habitan, con los animales, con el agua y con las especies, ahí han subsistido nuestras culturas por millones de años, los bosques no nascieron ayer señor García. [...] Nuestra Amazonia con sus ríos, cochas y quebradas albergan
$30 \%$ de agua dulce que existe en el mundo. ¿Dónde están las hectáreas ociosas señor García?, ¿Paradójico no? (AIDESEP 2007: 01-02)

Considerando estas quatro publicações e traçando um paralelo ao que analisa Latour (1994), o Estado de modo geral defende leis, mas possui suas alianças políticas que almejam projetos hegemônicos e arrasam as mesmas leis quando entende que a política não deve atrapalhar o desenvolvimento e o "laudo da ciência". Portanto, a Amazônia é compreendida pela razão moderna como o espaço da natureza que pode ser manipulado pelo conhecimento acadêmico legítimo sem que cosmologias tradicionais devam se intrometer, cosmologias estas que para o amálgama entre as visões burocrática, empresarial e científica significam tão somente a possibilidade retardar a exploração econômica "racional".

Ao mesmo tempo, a situação de tensão entre ambas as partes não é simplesmente dado pelos recursos naturais ou espaços, nem sequer pode ser resolvido por uma compensação financeira pela flora ou fauna eventualmente perdida ou modificada. A tensão é atenuada quando o pensamento indígena não é considerado como fonte de conhecimento real sobre as águas e os animais e, assim, os relatórios ditos científicos solapam ou minimizam suas reclamações. Assim sendo, o trecho “... onde estão os hectares ociosos, senhor Garcia?” torna-se apenas uma visão romântica da floresta intocada na interpretação hegemônica. Assim, as múltiplas confrontações que 
ocorrem podem reproduzir as dicotomias desequilibradas, tal como Santos (2008) mostra, nas quais o segundo termo da comparação (embora pareça simétrico ao primeiro) é sempre submisso e menor: moderno vs. tradicional, fato vs. crença, conhecimento universal vs. conhecimento local. Nesse sentido, aquele que não pretende ver as consequências do TLC sobre seu território, "a modernidade chegando", como promulgou a ex-ministra de Comércio Exterior, torna-se o perro del hortelano.

\section{OS DECRETOS LEGISLATIVOS}

A fim de fornecer subsídios à análise que empreendemos, faz-se preciso observar com maiores detalhes o conjunto de dispositivos que pode ser considerado a "gota d'água" do conflito instalado em Bagua. Em dezembro de 2007, o poder executivo pede ao Congresso da República a concessão de faculdades para expedir um conjunto de 102 normas em favor do mencionado Tratado de Livre Comércio, aprovando-se dita concessão pela lei no 29.157 . Observe-se que os decretos legislativos (DLs) possuíam numa natureza excepcional, pois o Executivo passou à figura de legislador. Quando promulgados, muitos destes entraram em conflito com Convenção 169 da Organização Internacional do Trabalho (OIT 1989) e a Declaração das Nações Unidas para os Direitos dos Povos Indígenas, dos quais o Peru é signatário. Entre os mais importantes DLs, todos contradizendo a constituição do país e a Convenção 169 da OIT, encontram-se no Quadro 1.
De outra parte, as comunidades indígenas defendiam os seus direitos de consulta. Como se não bastasse refletir sobre uma possível dimensão moral de escutar as populações que vivem nos espaços então tornados recursos para o capital, a Convenção 169 da Organização Internacional do Trabalho afirma que os povos nativos devem ser consultados diante de leis que envolvem os seus destinos. $\mathrm{O}$ artigo seis (itens 1 e 2) da Convenção é enfático:

1. Ao aplicar às disposições da presente Convenção, os governos deverão: a) consultar os povos interessados, mediante procedimentos apropriados e, particularmente, através de suas instituições representativas, cada vez que sejam previstas medidas legislativas ou administrativas suscetíveis de afetálos diretamente; b) estabelecer os meios através dos quais os povos interessados possam participar livremente, pelo menos na mesma medida que outros setores da população e em todos os níveis, na adoção de decisões em instituições efetivas ou organismos administrativos e de outra natureza responsáveis pelas políticas e programas que lhes sejam concernentes; [...] 2. As consultas realizadas na aplicação desta Convenção deverão ser efetuadas com boa fé e de maneira apropriada às circunstâncias, com o objetivo de se chegar a um acordo e conseguir o consentimento acerca das medidas propostas (OIT 1989).

Do mesmo modo, o artigo sete (itens 1, 3 e 4) da mesma convenção assinala:

1. Os povos interessados deverão ter o direito de escolher suas próprias 
Quadro 1

Decretos Legislativos (DL) e seus objetivos

\begin{tabular}{c|c|l}
\hline DL & Data & \multicolumn{1}{c}{ Objetivo } \\
\hline 994 & 13.03 .2008 & $\begin{array}{l}\text { Promove a ampliação dos projetos de irrigação podendo-se aproveitar } \\
\text { as terras de comunidades sem título de propriedade ou que estão } \\
\text { sobre a proteção de reservas ou patrimônio arqueológico. (Vigente). }\end{array}$ \\
\hline $1015^{a}$ & 20.05 .2008 & $\begin{array}{l}\text { Fica reduzida a quantidade de votos de 66\% mais um da comunidade } \\
\text { a 50\% mais um dos presentes na assembleia comunal para estabeleci- } \\
\text { mento de negócios e venda das suas terras a terceiros. (Revogado } \\
\text { após a primeira paralização das comunidades indígenas) }\end{array}$ \\
\hline 1020 & 10.06 .2008 & $\begin{array}{l}\text { Estabelece uma política de promoção agrária direcionada a criar } \\
\text { novas formas associativas no campo de orientação empresarial. } \\
\text { (Vigente). }\end{array}$ \\
\hline $1073^{b}$ & 26.06 .2008 & $\begin{array}{l}\text { Reforma o número de membros necessários para a tomada de de- } \\
\text { cisões das comunidades camponesas e nativas sobre as suas terras. } \\
\text { (Revogado após a primeira paralização das comunidades indígenas) }\end{array}$ \\
\hline 1064 & 28.06 .2008 & $\begin{array}{l}\text { Mantém um regime jurídico para o aproveitamento das terras de uso } \\
\text { agrário: os territórios das comunidades ficam vulneráveis às reclamações } \\
\text { de uso econômico feito por terceiros. Elimina o requisito de acordo } \\
\text { prévio entre a empresa e a comunidade campesina para iniciar as } \\
\text { atividades de exploração dos recursos do subsolo. (Revogado após } \\
\text { 06 de junho de 2009). }\end{array}$ \\
\hline 1081 & 28.06 .2008 & $\begin{array}{l}\text { Modifica Lei n. 27.262 - Lei Geral de Sementes. Promove a livre } \\
\text { entrada de sementes transgênicas ao país. (Vigente) }\end{array}$ \\
\hline Cria o Sistema Nacional de Recursos Hídricos. (Vigente)
\end{tabular}

${ }^{a}$ Em maio de 2008, a Defensoría del Pueblo interpõe uma ação de inconstitucionalidade contra o DL 1015 ao Tribunal Constitucional.

b A Defensoría del Pueblo declara que a o DL 1073 (que surge para corrigir o DL 1015) continua sendo inconstitucional dado que modifica o regime de disposição de terras das comunidades sem tê-as consultado. O DL 1073 também atenta o artigo seis da Convenção da OIT.

Fonte: Elaboração dos autores com base no Relatório sobre DLs vinculados aos povos indígenas promulgados pelo poder Executivo em mérito à lei 29.157, apresentado pela Comissão Multipartidária do Congresso em dezembro de 2008. 
prioridades no que diz respeito ao processo de desenvolvimento, na medida em que ele afete as suas vidas, crenças, instituições e bemestar espiritual, bem como as terras que ocupam ou utilizam de alguma forma, e de controlar, na medida do possível, o seu próprio desenvolvimento econômico, social e cultural. Além disso, esses povos deverão participar da formulação, aplicação e avaliação dos planos e programas de desenvolvimento nacional e regional suscetíveis de afetá-los diretamente. [...] 3. Os governos deverão zelar para que, sempre que for possíve1, sejam efetuados estudos junto aos povos interessados com o objetivo de se avaliar a incidência social, espiritual e cultural e sobre o meio ambiente que as atividades de desenvolvimento, previstas, possam ter sobre esses povos. Os resultados desses estudos deverão ser considerados como critérios fundamentais para a execução das atividades mencionadas. 4. Os governos deverão adotar medidas em cooperação com os povos interessados para proteger e preservar o meio ambiente dos territórios que eles habitam (OIT 1989).

Sabendo que a Convenção os defendia e que os decretos eram inconstitucionais no ponto de vista da defensoria pública, somados ao fato do Congresso Nacional estar sem reação frente aos atos do Executivo, em agosto de 2008 as comunidades empreendem um conjunto de ações de resistência como parte da "Gran Mobilización Nacional Indefinida de los Pueblos Indígenas". As ações não se fizeram esperar. Já no dia nove de agosto, um grupo de cerca de 2.000 membros da etnia indí- gena Machiguenga capturou 10 embarcações de transporte de combustível pertencentes à empresa Pluspetrol, da Argentina (em Quillabamba, Cusco). No dia seguinte, cerca de 600 Awajun ingressaram nas instalações de Petrope$\mathrm{ru}^{5}$ (em Loreto) tomando o controle da válvula principal. Igualmente, um grupo ocupou a Central Hidroelétrica de Aramango (em Amazonas). Posteriormente, como num efeito em cascata, comunidades nativas do Bajo Urubamba tomaram os poços de Pagoreni $\mathrm{A}$ e $\mathrm{B}$, plataformas, heliportos $\mathrm{e}$ acampamentos do lote 56 pertencentes à Plusterol; e no Marañon, grupos indígenas empreenderam ação paralisando a estação petroleira $n^{\circ} 5$ e a estação $\mathrm{n}^{\circ} 6$ do Oleoducto Nor Oriente (em Amazonas).

Com tal inervação social, o Congresso se vê obrigado a anular os decretos legislativos 1015 e 1073, ainda que para isso tenha que enfrentar o contragosto do presidente Alan García, o qual não deixou de opinar, falando à imprensa, que isto significou um grave erro de dimensões históricas e que condenará as comunidades no interior do país à decadência e à exclusão. Nos meses que se seguiram, houve um conjunto de tentativas de se estabelecer "mesas de diálogo"; todavia a negociação era minada por antagonismos internos à sociedade peruana. Logo, a AIDESEP decidiu abandonar o diálogo implementado pelo Poder Executivo em setembro de 2008 devido à (in)conveniente permanência dos dirigentes da Confederación de Nacionalidades Amazónicas de Peru (CONAP), or- 
ganização vinculada a empresas petroleiras e abertamente uma defensora dos interesses do governo. Nesse mesmo mês, é instalada pelo Congresso da República a "Comisión Multipartidária” responsável por estudar a problemática indígena e propor políticas públicas para a sua solução. A prioridade consistia em analisar se os DLs 994, 1064, 1020, 1080, 1081, 1089, 1090, 1083, 1060 e 995 afetavam direitos dos povos indígenas, avaliar a viabilidade da implementação da Convenção 169 da OIT, particularmente a incorporação da consulta prévia, e examinar a aplicação das políticas públicas especiais.

Para cumprir com esta finalidade, foram convidados representantes de organizações, entre as quais AIDESEP, OIT, Confederación Nacional Agraria (CNA), Confederación Campesina del Perú (CCP), Confederación Nacional de Comunidades del Peru Afectadas pela Minería (CONACAMI) e Coordinadora Andina de Organizaciones Indigenas (CAOI).

Ainda em dezembro de 2008, a comissão de constituição do Congresso aprovou o relatório com o objetivo de ser debatido no dia $1^{\circ}$ de fevereiro de 2009 no plenário do Congresso ${ }^{6}$. No entanto, e provavelmente por razões não aleatórias, no mesmo dia entra em vigência o Tratado de Livre Comércio com os Estados Unidos e passa-se a um "novo" problema (ou um novo momento), e desconsidera-se, em seguida, o fato de que relatório sequer chegou a ser apresentado ao Congresso. Dito relatório "reafirmava" que os
DLs questionados são inconstitucionais por violar artigos e disposições da Constituição do Peru.

Paralelamente, no dia 16 de dezembro, foi aprovado, pela Comisión de Pueblos Andinos, Amazónicos, Afroperuanos, Ambiente y Ecología (CPAAAAE) do Congresso o projeto de lei 2.691 alternativo ao questionado DL 1090 (Lei da Selva). O seguinte passo administrativo seria a aprovação no plenário do Congresso em janeiro de 2009, que nunca chegou a ser votado. $\mathrm{O}$ fato provocou revolta em parte dos congressistas, sem comentar o descontentamento nas comunidades. Além destes problemas, de outro lado, os projetos de lei 2.959 e 2.958, elaborados pelo Executivo e sustentados pela ex-ministra de Comercio Exterior, foram aprovados sem demora pelo congresso no mesmo janeiro de 2009.

Nesse meio tempo, as comunidades indígenas observavam a movimentação política. Aglutinaram-se diversas organizações para manifestar desagrado com os andamentos da negociação, como as já mencionadas AIDESEP, CCP, CONACAMI, e CAOI. Alberto Pizango, líder da AIDESEP, reitera que as mobilizações continuam a ter por objetivo a anulação dos decretos, mas a própria situação propensa a estabelecer um diálogo mudou:

Debo insistir en que la movilización no es por la instalación de la mesa de diálogo, sino por la derogatoria de los nueve decretos legislativos. Eso hay que entenderlo bien. Estamos en marcha ahora y ya hay un decreto legislativo (1090 Ley Forestal y de Fauna Silvestre) que 
está pendiente de resolverse en el Congreso. (Pizango 2009: 04)

Essa condição mostra o crescimento da tensão social. A partir do dia nove de abril de 2009, diante da indiferença dos poderes executivo e legislativo, houve uma paralização por tempo indeterminado das comunidades indígenas dos departamentos de Bagua (Amazonas), Yurimaguas (Amazonas), Iquitos (Loreto), Puerto Maldonado (Madre de Dios), Quillabamba (Cusco), Pucallpa (Ucayaly). Mais adiante, envolvem-se na paralização as cidades de Satipo (Junin), Atalaya (Ucayaly), Datem del Marañon (Loreto) e Kichuas del Putumayo (Loreto, fronteira com a Colômbia). Na última semana de abril, centenas de indígenas Awajún e Wampis tomaram controle da estação $n^{\circ} 6 \mathrm{da}$ PetroPeru e em Putumayo é impedido o ingresso das embarcações da Petrobrás.

Pizango se reúne com o então premiê Yehude Simon para reestabelecer o diálogo, mas não chegam a consenso. Especificamente, as demandas das populações amazônicas neste momento eram:

1. Revogação dos decretos legislativos 1020, 1064, 1089 e 1090 que atentam contra os direitos dos povos indígenas, assim como a revogação da lei 29.317 (modifica o DL 1090) e a 29.339, nova lei de recursos hídricos.

2. Reforma da Constituição Política do Estado para restituir os direitos territoriais indígenas como inalienáveis, não passíveis de embargo e imprescritíveis, e o reconhecimento dos direitos coletivos dos grupos enquanto povos indígenas.

3. Ocompromissodogoverno com a não criminalização dos protestos sociais.

4.Constitucionalizar a Declaração das Nações Unidas sobre direitos dos povos indígenas e a Convenção 169 da OIT.

5.A aprovação de uma lei geral que obrigue o Estado e as suas instituições a incorporar o direito de consulta prévia em todos os procedimentos legislativos e administrativos assim como na regulamentação das normas que afetam os direitos dos povos indígenas, consulta que deve ser obrigatória e com resultados de caráter vinculante.

6.Estabelecimento de diálogo em nível nacional para implementar demandas dos povos indígenas das diferentes regiões andinas e amazônicas do Peru. (AIDESEP 2009: 1)

Após a reunião, Yehude Simon declara que Pizango conversava com ele em castelhano, mas por telefone se dirigia aos "nativos" na sua língua, duvidando da veracidade da tradução. No dia 15 de maio, em Lima, numa conferência de imprensa, Alberto Pizango comunica às bases que o governo federal "está com pouca vontade" de solucionar os problemas e atender às exigências dos povos amazônicos. Informa ainda que as reuniões com o premiê Yehude Simon e o presidente do Congresso Velásquez Quesquén “não serviram de nada e foram manobra [para dilatar o prazo]". Ademais, o líder aproveita para fazer um chamado à insurgência, rechaçar o Estado de emergência que havia sido imposto pelo governo devi- 
do às paralisações e, num ato de rebeldia, colocar em vigências as próprias leis e os costumes indígenas. Após perceber a radicalização, Pizango se retrata. Contudo, o episódio já havia se tornado politicamente explosivo. Dias mais tarde, Alberto Pizango é denunciado pelo procurador da Presidência de Conselho de Ministros por rebelião e conspiração contra o Estado.

\section{"EL BAGUAZO"}

Um dia anterior ao violento confronto (conhecido agora como "El Baguazo”), o plenário do congresso, reunido para decidir sobre a revogação do DL 1090, aprova um pedido para postergá-lo, já que precisavam do Relatório Final resultante das negociações entre o premiê Yehude Simon e o dirigente AIDESEP. Curiosamente, o diálogo já não existia mais, fato de conhecimento geral. Rememorando, Santiago Manuin, dirigente das comunidades Aguaruna-Huambisa da província de Condorcanqui, declara:

El 3 de junio en una asamblea interna [...] se tomó la decisión (regresar) porque el Congreso había postergado de revisar los decretos y tenía que hacer eso, y entonces la gente se reunió, porque una parte estaban cansados y para hacer cambios era muy costoso porque ya faltaba movilidad, entonces lo que sucedió fue que toda la gente el cinco iban a abandonar, a las 9 de la mañana iban a dar el pase, iban a quedarse unos dos o tres días para reorganizar el regreso es decir dar todos los pase a todas las camionadas que estaban ahí después de tres días íbamos a conseguir la movilidad una vez normalizando para el traslado de la gente para allá y por eso íbamos a, es decir, pedir apoyo a Jaén, pedir apoyo a Utcubamba, pedir poyo nuevamente a Bagua y nuevamente conversar con los madereros para que nuevamente nos vuelvan apoyar con el traslado y regreso [...]. (Comisión Especial 2009: 50).

O relatório da comissão que investigou o acontecido em Bagua recolhe também o testemunho de Salomón Awanash Wajush, presidente do Comitê de Luta Nacional Amazônica dos Povos Indígenas. O dirigente relata sobre a reunião com o general da Polícia Nacional Peruana (PNP), Javier Uribe, responsável pela operação do dia quatro de junho:

Nosotros le pedimos al general una tregua para salir de la carretera. Junto al obispo de Jaén le pedimos una tregua hasta las 10 de la mañana del viernes 5. Lo aceptó con la condición de que el único punto de la agenda era arreglar el pase y que si no abríamos la carretera luego de eso iba a restaurar el orden a la fuerza. Nosotros le preguntamos qué haría si recibía la orden antes de esa hora y dijo que así recibiera la orden de Lima, él nos esperaría hasta las 10 de la mañana porque su gente no haría nada sin su orden, que confiáramos en su palabra. Pero a las 5 y 50 de la mañana la policía comenzó a aparecer por el cerro de la Curva del Diablo. Me sorprendí y traté de ubicar al general Uribe. Llamaba al celular del general pero no contestaba, estaba apagado. (Awanash Wajush 2009:57) 
De outro lado, o general Uribe, defende a sua posição:

Yo les puedo decir de las negociaciones que hicimos el domingo 30 , se notaba que no había una unidad; entre los Apus [chefes indígenas], habían quienes estaban a favor y quienes estaban en contra de liberar carretera, inclusive ese día podríamos decir que hubo un "cisma" entre comillas, porque muchos se replegaron ese día, cuando se abre el tránsito por tres horas parece que hubo un resentimiento al interior y algunos grupos se replegaron, era evidente que habían grupos encontrados, pero siempre había el discurso confrontacionista de algunos que hacían referencia a que justamente ellos tenían licenciados, tenían combatientes del Cenepa y que no iba a ser fácil desalojarlos a ello y todo eso está escrito en los documentos, en las apreciaciones [...]. (Comisión Especial 2009: 45).

O Monsenhor Santiago García de la Rasilla, bispo de Jaén, testemunha da reunião entre Wajush e o Gal. Uribe, declara para a Comissão Especial que as ações dependiam do comando em Lima, mas que havia tratativas em curso entre a população local e as forças policiais. O bispo afirma ainda que no trâmite estava a discussão dos decretos que poderiam mudar rumos da negociação. Atuando parcialmente como mediador, ele menciona que havia ordens expressas para retirar os indígenas das instalações e estradas, sem que o diálogo fosse priorizado.

Mesmo assim várias versões parecem coincidir que entre as cinco e seis da manhã do dia cinco de junho de 2009, um grupo de 369 membros da Policia Nacional do Peru (PNP), da Dirección de Operaciones Especiales (DINOES) e efetivos do Exército realizaram uma operação para reprimir as manifestações e encerrar o fechamento de estradas; no entanto, não esperavam tal radicalidade da resposta indígena. O episódio tomou lugar em um trecho da estrada Fernando Belaúnde Terry conhecido como a "Curva del Diablo", que conduz às cidades de Bagua (província de Bagua) e Bagua Grande (província de Utcubamba), ambas no departamento de Amazonas. Conforme grupos presentes no local, relatados por relatórios da Anistia Internacional, a polícia iniciou o confronto contra indígenas que portavam lanças disparando bombas de gás lacrimogêneo e usando fuzis AKM a partir de pontos estratégicos, tais como cerros e helicópteros.

Numa distância de 80 quilômetros da "Curva del Diablo", manifestantes que ocupavam a estação $n^{\circ} 6$ da empresa petroleira estatal Petroperu (em Imaza) reagiram ao saber da notícia da operação policial, matando onze agentes que os tinham retido. Relatado por dois suboficiais que estiveram na estação $n^{\circ} 6$, estes mostram que houve tentativas de negociação alegando-se que os dois eventos (em Imaza e na Curva) eram distintos. Mas a presença de um grande número de comuneros, que haviam assistido a cobertura do episódio, exacerbou os ânimos e ofereceu pouco espaço para dialógo. Os suboficiais garantem que havia 18 policiais na estação e que apenas sete sobreviveram.

Dados controversos sugerem que o 
enfrentamento ocorreu por iniciativa da polícia, fato agravado por ela ter agido antes de esgotar possibilidades de tratativa. No entanto, os mesmos dados mostram que lideranças indígenas se pronunciaram pró-conflito, elemento que foi somado à impaciência e morosidade dos poderes executivo e legislativo. Os depoimentos demonstram que, além do executivo ter maior poder em todo o processo, entre os dias quatro e cinco de junho ordens do próprio poder executivo podem ter sido o estopim (informação não confirmada, mas todas as investigações levam ao fato da ordem partir de altos comandos governamentais).

Após o trágico evento, os jornais nacionais veiculam somente a morte dos 24 policiais, doze dos quais mortos durante a batalha para remover os grupos locais. Relatos afirmam que na "Curva" os indígenas enfrentaram os batalhões no "corpo a corpo" conseguindo retirar algumas de suas armas e os ferindo igualmente com as lanças. No entanto, pouca ênfase apareceu nos meios de comunicação a respeito da morte das populações indígenas envolvidas.

Após o pronunciamento do presidente do país sobre a morte dos policiais e certo descaso sobre a morte e desaparecimento de pessoas ligadas às comunidades, o governo tenta abafar o caso e minimizar sua culpa. Tal como os artigos publicados em jornais pelo presidente, discurso semelhante é utilizado dois dias depois do incidente, mas desta vez com apelação midiática e em tom de exacerbar fraturas sociais. Uma das campanhas publicitárias dizia: "12 milhões de hectares para 400 mil nativos? 15 milhões de hectares como santuários naturais?" $\mathrm{Na}$ tarde do mesmo dia, o presidente do Peru expressa em entrevista à prensa.

Ya está bueno, estas personas no tienen corona, no son ciudadanos de primera clase que puedan decirnos 400 mil nativos a 28 millones de peruanos tu no tienes derecho de venir por aquí, de ninguna manera, eso es un error gravísimo y quien piense de esa manera quiere llevarnos a la irracionalidad y al retroceso primitivo (García Perez, 2009).

O presidente expressa que o destino do país e seus milhões de habitantes pode (e deve) ser decidido apenas por "cidadãos de primeira classe", certamente uma expressão que precisaria de explicação, mas que permite interpretações. Adicionalmente, os indígenas são caracterizados como primitivos, não-civilizados e irracionais. Se os apelos à democracia formal encontram poucos ecos, a proposta mais radical da biodemocracia e as tentativas de entendimento entre culturas distintas é algo distante do horizonte político.

\section{COSMOLOGIAS DIVERSAS E CONEXÕES TEÓRICAS: ALGUMAS EXPERIÊNCIAS}

O que é particular de se notar, infelizmente, é que o caso de Bagua no norte do Peru, embora um evento de explosão de brutalidade, não é raro no modo de dominação que se exerce no panorama das relações entre Estado, elites, povos tradicionais e "recursos" naturais ou minerais.

Marisol de la Cadena, antropóloga 
peruana, mostra outras situações no sul de seu país que são similares. $\mathrm{Na}$ região de Ausangate (região de Cusco), montanha que tem um sentido muito especial para camponeses indígenas, a mineração também avança em ritmo acelerado e os projetos de "desenvolvimento" impetrados pelo Estado em conjunto com grandes corporações advoga o acesso aos recursos presentes neste espaço como essencial para o crescimento econômico da nação e o retorno de benefícios às comunidades. Enquanto isto, comuneros se rebelam para impedir o avanço e são taxados pelo governo de "velhos comunistas" que emperram o progresso e, agora, são ainda nomeados com "roupagens ambientalistas", conforme de la Cadena (2010). Seus apelos, entretanto, são mais profundos do que um mero "estar contra" as corporações capitalistas: as ações coletivas esboçam sua compreensão de mundo em que os seres naturais não são separados dos humanos tal qual a ontologia dualista moderna reconstitui (Escobar 2008).

Vale a pena detalhar o argumento que de la Cadena apresenta. Em suas incursões em pesquisa de campo, entrevistou e acompanhou muitos camponeses. Neste ínterim, quando perguntados pela antropóloga qual seria a questão essencial que sustentava suas lutas contra empresas mineradoras, um dos interlocutores locais afirmou que, ao inverso de como pensava a autora, não são apenas as pastagens e os estabelecimentos rurais que podem se perder, mas a montanha sagrada não permitiria a atividade mi- neira, ela poderia se enfurecer e até mesmo provocar a morte de pessoas.

Uma literatura trivial focaria a perspectiva do entrevistado como mágica, permanecendo uma falsa consciência dos processos do mundo real. No entanto, o que Marisol de la Cadena destaca é justamente a capacidade desta visão de mundo romper com as formas pelas quais o mundo da modernidade tem pensado as relações sociais e a interação entre sociedade e natureza. Para os camponeses, os seres "outros-quenão-humanos" não deixam de ser seres que sentem, portanto possuem uma capacidade de agência ${ }^{7}$.

Esse é o ponto de vista privilegiado neste trabalho. "Levar a sério o discurso nativo" (Goldman 2008) é mais que traduzi-lo numa linguagem aceita pelos jargões intelectuais acadêmicos estabelecidos e que priorizam um tipo de interação social e um modo único de fazer política. Seguindo os escritos Marisol de la Cadena (2010), Viveiros de Castro (2002) e Marilyn Strathern (2006a), entender o que é social e político passa antes pelo que as categorias do discurso nativo relacionam como social e político, não a partir de um a priori, o que necessariamente fará com que o que se considera como a "política real" seja ampliada em termos de sentido e de práxis.

A montanha e os demais elementos 'naturais', numa época de exacerbada exploração econômica - que vai do gene ao mineral, da floresta produzida artificialmente aos tesouros escondidos da Antártida -, revelam uma face diferenciada quando observada 
desde o olhar dos povos tradicionais. Três são os conceitos-chave que apreendem bem estes fenômenos: rede, relacionalidade e perspectiva. Eles remetem que relações são traçadas num âmbito mais complexo do que geralmente supomos. Pois, se conflitos como estes podem ser vistos em consonância aos problemas que a economia política e a ecologia política revelam sobre a luta pela distribuição de recursos econômicos e naturais, sugerem que essa mesma luta não acontece com base num mesmo sistema de signos e cosmovisões. A luta não é somente pelos "recursos", mas sobre o tratamento de uma entidade ser denominada como "recurso", por isto a noção de perspectiva como algo que constitui o mundo.

Tomado emprestado de Law (2004:157), o conceito de rede diz respeito ao conjunto de entidades e materialidades (e seus efeitos relacionais) em que se explora efetivamente a configuração destas relações. Contudo, além de materialidades, dando-nos o direito aqui de parafrasear Latour (1994:12), as redes são "reais como a natureza, narradas como os discursos e coletivas como a sociedade". Portanto, um ponto de vista relacional recupera o que as diferentes sociedades propõem como aquilo que é central nas suas relações, dessa forma também apostando no problema da perspectiva ${ }^{8}$.

Um caso de exploração mineradora bastante distante do Peru pode ajudar a esclarecer problemas teóricos até aqui apresentados. Stuart Kirsch, num trabalho realizado na Melanésia, mostra como os sistemas de relações entre seres humanos e entidades naturais evoca uma extensão que não é bem entendida nos grandes projetos de desenvolvimento. Kirsch (2001) demonstra que as empresas que entram no território dos povos tradicionais geralmente fornecem algum tipo de compensação às pessoas, especialmente na forma de dinheiro que, ao nosso entendimento, é a forma mais rápida de destituir um conflito e despolitizar os anseios reprimidos das populações destes lugares.

Os grupos que continuam a residir nas proximidades da atividade mineradora, entretanto, evocam um tipo de relação com o espaço e com a própria empresa que os gerentes de corporações pouco compreendem. Kirsch cita o caso de camponeses que foram compensados financeiramente e que, mesmo assim, esboçam claramente que a relação não termina ali na transação financeira. $\mathrm{O}$ antropólogo sustenta que um dos fatores que motiva os desacordos entre ambas as partes - camponeses e mineradora - é o estresse causado por duas diferentes formas de interpretar o intercâmbio. Ao contrário da corporação, interessada em compensar e se livrar da população local tão logo as terras sejam adquiridas, as sociedades denominadas como "não-modernas" buscam a perpetuação da relação com a outra parte (a empresa, no caso) do mesmo modo que há séculos se mantêm entre as comunidades da ilha.

Antes de detalhar a análise, observemos um processo semelhante revelado numa comunidade andina do Peru, descrito por Damonte (2007). Quando a em- 
presa mineradora Antamina comprou as terras da comunidade de Angoroju Carhuayoc, a comunidade decidiu investir o dinheiro recebido pela compra das suas terras na compra de caminhões para que a própria empresa contratasse seus serviços de transporte. Claramente, a proposta da comunidade era manter o laço de trocas entre camponeses e empresa, tal como a cosmologia comunitária advoga. A Antamina, num primeiro momento, não quis contratá-los, alegando que as camionetas precisavam de equipamento adicional para serem utilizadas.

Fatalmente, para os camponeses a negativa da empresa correspondia a uma tentativa de quebrar a rede de relacionalidades que a mesma mineradora havia construído com os grupos locais no momento de compra das terras. Salas (2002) argumenta que, nesta ocasião, os camponeses não aceitavam a natureza da relação que a empresa adotava. Enquanto para a mineradora a relação acabava no ato da compra, a relação de intercâmbio para a comunidade é de longo prazo e constitui um sistema de trocas. $\mathrm{Na}$ realidade, o que chama a atenção, parece-nos, que nomeamos fatos aparentemente similares com o mesmo conceito (compra ou venda/trocas intermitentes) e, de um ponto de vista e outro, equívocos interpretativos surgem no entendimento de atores em diferentes perspectivas ${ }^{9}$.

Ora, o sistema de propriedade que a ontologia euro-americana moderna legitima supõe que a propriedade não é uma relação entre pessoas e coisas, mas uma relação entre pessoas por meio de coisas (Strathern 2006b) ${ }^{10}$. As coisas tratadas como propriedades separam as pessoas, elas cortam as redes, porque estes objetos permanecerão efetivamente ligados aos seus proprietários. Mas as reclamações por compensação na Papua Nova-Guiné e no Peru mostram as relações entre pessoas e coisas. Neste sentido, gerentes de empresas veem as populações locais como aproveitando das benesses da companhia mineradora para obterem vantagens materiais, porém a relacionalidade é tão enraizada em seu pensamento que não é simples romper esse modo. Obviamente, alguma vantagem estratégica os camponeses procuram; Kirsch (2001) também reconhece, no entanto isto é pouco para entender os fatos.

Portanto, essa é a expressiva capacidade que a noção de relacionalidade (Strathern 2004, Escobar 2008) sugere: vincular pessoas e suas extensões, não apenas naquilo que o mundo jurídico moderno considera legítimo como produtos do trabalho ou do pensamento (tal como as formas de propriedade intelectual e os seus inventores), mas as relações reais que se formam em conexões entre pessoas, seres não-humanos e objetos e que $d e$ fato constituem as pessoas como elas são.

Por fim, gostaríamos de recuperar um caso, no Brasil, que possui algumas diferenças essenciais quando comparado aos anteriores, como relata a monografia de César Gordon. Realizando extensa pesquisa entre os índios Xikrin-Mebêngôkre no norte do Brasil, Gordon (2006) mostra as relações deste grupo com a companhia Vale do 
Rio Doce, empresa brasileira e uma das maiores exploradoras de minério de ferro do mundo. A empresa inicia as atividades nas proximidades do território deste povo, o que, ao longo dos anos, torna a corporação obrigada a compensar os índios. Com certa facilidade, a população aceita as compensações financeiras, porém o caso se diferencia dos anteriores porque a empresa precisou manter a relação intermitente com o grupo, em razão dos índios ainda habitarem a região. Ao contrário dos casos do Peru e da Papua Nova-Guiné, a empresa oficializou um contrato com a tribo indígena para pagamentos à comunidade ao longo dos anos. Gordon (2006) mostra, entretanto, que a presença da empresa na região causou um impacto no mínimo curioso ao sistema social local: a Vale do Rio Doce se vê obrigada a um aumento constante e expressivo dos recursos monetários destinados ao grupo.

A cada ano o montante repassado, já de uma ordem bastante razoável, é pressionado para ser acrescido pelos líderes indígenas. Este fato é ocasionado por um conjunto de razões, mas segundo Gordon, dentre as principais está a "inflação do consumo" no interior do grupo. Em verdade, a etnografia de Gordon (2006) demonstra que o universo simbólico da população indígena entroniza os itens modernos no seu sistema ritual, não deixando de serem efetivamente índios Xikrin-Mebêngôkre. Mesmo assim, a interação constante com a companhia teve efeitos diretos e imprevisíveis no modo como a população passou não apenas a de- pender dos recursos vultosos como a espiralar a importância das finanças no sistema de prestígio interno à sociedade indígena. Impacto positivo ou negativo, não cabe julgar, o que destacamos é que esta experiência não deixa de ser um caso de excepcional relevância para sublinhar que as partes contraem relações desequilibradas e incorporam perspectivas diferenciadas.

\section{INTERCULTURALIDADE, BIODEMOCRACA EOPLURIVERSAL: CONSIDERAÇÕES FINAIS}

Essa conexão entre visões de mundo não oferece alternativas fáceis para o empreendimento de um diálogo; sob os auspícios da razão moderna a supressão da diferença não encontra resultados que não sejam violentos (ou como Boaventura de Souza Santos repetidamente afirma "não existem saídas modernas para os problemas da modernidade"). Se a modernidade permite uma diferença controlada na medida em que se ancora em dimensões tais como valor intrínseco do indivíduo, o saber científico, a regulação por ordem jurídica do direito moderno, a forma mercadoria e outras, esta difícil dialogia encontraria formas se interrompesse a tentativa de "enquadramento" sociocultural numa armadura artificial unitária para explorar a própria diferença radical.

O caso de Bagua mostra justamente que os grupos indígenas desejavam o diálogo, mas a suspensão dessa possibilidade foi dada pela burocracia estatal e pelo poder pessoal do presidente do Peru. Na realidade, o que mais os 
grupos desejavam? Santiago Manuin, recebedor do Prêmio Rainha Sofia em 1994 (na Espanha) pelo seu compromisso com o ambiente e os direitos humanos, esclarece a ideia de desenvolvimento para as comunidades indígenas:

No estamos en contra del desarrollo ni de la inversión, los necesitamos. Pero queremos saber, nunca somos consultados, nunca nos dicen qué quieren hacer con nosotros y nuestras tierras. No nos dicen cómo va a ser el futuro que se imaginan para nosotros, cuál va ser nuestro beneficio, cómo se asegura que nuestros hijos sigan viviendo del bosque y cómo se va a cuidar ese bosque. Necesitamos una inversión trabajada, un desarrollo desde la selva y a favor de la selva. Los verdaderos interlocutores están en la selva y los dirigentes y jefes están allá. No es suficiente el diálogo con unos pocos dirigentes. Tenemos nuestros equipos de trabajo, nuestras organizaciones en los ríos, que vengan a hablar. Pizango no era suficiente (Manuin 2009: 24-25).

Santiago Manuin deu este depoimento à revista Somos após o evento no hospital do município de Chiclayo, sendo testemunha viva do que ocorrera - ele próprio alvejado com oito tiros e um dos primeiros a serem feridos. Por sua parte, Daysi Zapata, vice-presidente da AIDESEP, sustenta que o "desejo de diálogo" dos grupos locais promove uma ampliação de noções e conceitos com o que os setores hegemônicos lidam, por exemplo, no que se constitui o desenvolvimento sustentável:

Los pueblos indígenas siempre miramos un desarrollo sostenible, nosotros cuidamos, por ejemplo sacamos las maderas y vamos reforestando. Lamentablemente, este gobierno está impulsando un desarrollo dentro de sus conveniencias. Por ejemplo, tenemos lotes petroleros dentro de comunidades nativas. Todas usan malas metodologías porque dejan el ambiente y los ríos contaminados. Si hubiera una forma de explotar bien el petróleo sería magnífico, pero eso no pasa. Hay un lote petrolero de Repsol que está en la quebrada Mashansha (Ucayali). La exploración la hacen en la parte alta y la gente que vive en la parte baja toma el agua y se enferma. Hay que ir a la zona para ver cuál es la realidad, porque cuando hablan los señores de las petroleras hablan bonito, hablan lindo, pero no cumplen los estándares que pide el gobierno. Eso hace que nuestros árboles, quebradas y peces vayan muriéndose (Zapata, 2009).

Daysi Zapata, que tem a intenção de denunciar à Corte Interamericana de Direitos Humanos a perseguição dos dirigentes da associação que representa, supõe a inexistência de métodos de utilização do ambiente que sejam menos danosos que os indígenas. Portanto, está no caráter do conhecimento do lugar e a imersão das pessoas que o habitam, para as quais as tecnologias das empresas não oferecem soluções satisfatórias para sustentabilidade da vida. Na opinião de Alberto Pizango, poder aceder a outro olhar (crítico, reconstrutivo) sobre o desenvolvimento se transmuta para uma apreensão de que a população indígena menospreza qualquer mudança social, econômica ou tecnológica. Pizango exlamou em uma entrevista coletiva à imprensa: 
Nosotros no estamos en contra del desarrollo como se nos acusa. Nosotros queremos el desarrollo, pero desde nuestra propia perspectiva (...) ¿De qué nos sirve tener luz, agua, teléfonos satelitales, si vemos a nuestras comunidades destruidas e inundadas por las plagas sociales? (Pizango 2009 - itálico adicionado)

Neste caso preciso, a exploração da "natureza" e a sua utilização que inviabiliza esforços em direção à biodemocracia (Escobar 1999) foram responsáveis pelo conflito, sugerindo que os vetores da globalização não conseguem ter a energia suficiente para demarcar efetivamente um mundo universalista, no qual não haja espaço fora da modernidade e do capitalismo (Escobar 2008, Quijano 1991). Ao invés do caminhar em direção ao universal ser o objetivo primordial das nações globalizadas do início do século XXI, Marisol de la Cadena sugere antes visibilizar o pluriversal. O pluriversalismo se orienta a incluir a diferença sem sua supressão.

A noção de pluriversal encontra ressonâncias no conceito de multiplicidade, trabalhado por muitos autores, como Law (2004), e atribuído ao pensamento deleuziano. A partir dela, é preciso observar

[...] o clamor de que existem muitas realidades ao invés de uma. Isto ocorre porque práticas são infinitamente variáveis e diferem uma das outras. O clamor adicional de que práticas se sobrepõem de diferentes e imprevisíveis maneiras, portanto há sempre interferências entre as diferentes realidades.
Multiplicidade é inconsistente com singularidade, mas também com pluralismo (Law 2004:162).

Multiplicidade é inconsistente com singularidade e pluralismo. Ora, Law aponta que a ciência como resultado e também fonte do pensamento racional do Ocidente não consegue escapar das armaduras do único e do muitos: ou as coisas se resolvem no realismo simplório ou elas se tornam absolutamente relativas. A multiplicidade, entretanto, contorna as opções salientando que perspectivas e pontos de vista podem se suplementar; elas se sobrepõem com conexões, mas as conexões, parafraseando Strathern (2004) serão sempre parciais, o que faz com que nenhum ponto de vista seja subordinado ao outro.

Mas a multiplicidade, como conceito, não é entendida como fundamento do multiculturalismo; na realidade, é diametralmente distinto do multiculturalismo. Não é surpresa que Mignolo (2005), um dos defensores da "produção incessante da diferença", critique as opções dos Estados pelo multiculturalismo. Mignolo, evidentemente, não está advogando o universalismo, o que ele recupera é a noção (sublinhada por movimentos sociais indígenas) de interculturalidade:
Multicultural significa que princípios hegemônicos de conhe- cimento, educação, os conceitos de Estado e governo, economia políti- ca, moralidade, etc., são controla- dos pelo Estado, e abaixo do con- trole do Estado a população tem "liberdade" para seguir com suas "culturas" desde que não desafiem "os princípios epistemológicos" que fundamentam a política, a eco- 
nomia e a ética tal qual são administrados pelo Estado. "Interculturalidade", ao contrário, como utilizado em projetos políticos indígenas, significa que há duas distintas cosmologias em relação, a Ocidental e a Indígena (Mignolo 2005: 118).

Propositadamente, deixamos uma breve aproximação conceitual de interculturalidade para o final do trabalho, por entendermos que o esforço descritivo e analítico ao longo do texto (com base no caso examinado) permite uma apreensão sobre este princípio que ainda tem curta história nas ciências sociais. O episódio em Bagua sinaliza bem o que as opções pelo universalismo (e mesmo a tímida e limitada tentação do multiculturalismo) efetuam. O repensar da modernidade, que a crítica intra-europeia já formava com clareza pelo menos desde Nietzsche, recupera energia nos movimentos sociais indígenas contemporâneos. Suas ações auxiliam a vislumbrar o efeito de colonialidade que a modernidade gerou e sobre a qual se construiu, sendo a colonialidade da natureza apenas uma forma particular.

\section{NOTAS}

1 A publicidade mostrou imagens dos corpos dos policiais, seus familiares e indígenas com lanças em posição de guerra. A exposição da publicidade foi uma das razões pelas quais a ex-titular do Ministério da Mulher, Carmen Vildoso, renuncia ao seu cargo, dado que discordava com o tipo de informação que o governo circulava.

${ }^{2}$ Conforme o informe do mês de junho de 2009 da Defensoría del Pueblo (órgão autôno- mo que protege os dereitos constitucionais e fundamentais da pessoa e da comunidade no Peru), 273 conflitos foram registrados nesse mês, dos quais 127 (47\%) correspodem a conflitos categorizados como socioambientais.

3 A expressão "El perro del hortelano" [o cachorro do horticultor] tem origem na obra teatral de Lopez de Vega de mesmo título e é metáfora para nomear pessoas que não agem, mas também não permitem a outros agirem. O horticultor é o dono da horta e seu cachorro é quem a cuida, porém o último não a come, e, como responsável, também não deixa que outros a usurpem.

${ }^{4} \mathrm{Um}$ dos parágrafos do artigo " $\mathrm{El}$ síndrome del perro del hortelano" diz: "Y contra el petróleo, han creado la figura del nativo selvático 'no conectado'; es decir, desconocido pero presumible, por lo que millones de hectáreas no deben ser exploradas, y el petróleo peruano debe quedarse bajo tierra mientras se paga en el mundo US $\$ 90$ por cada barril. Es preferible para ellos que el Perú siga importando y empobreciéndose."

${ }^{5}$ Vale recordar que muitas das ações eram amparadas em fatos relacionados a problemas ambientais causados pelas empresas, tais como derramamentos de produtos em terra e águas.

${ }^{6} \mathrm{Na}$ sessão do dia 16 de dezembro, o congressista Juan Perry Cruz expressou indignação contra José Vargas, que solicitou ampliação do prazo para a entrega do relatório, sem consultar colegas, quando o documento parecia estar finalizado.

${ }^{7}$ Diferentes autores chegam a resultados semelhantes. Observe-se, por exemplo, a proposta do biólogo Brian Goodwin (2007) sobre sentient beings e a de Francisco Varela (1999), um dos expoentes da teoria da complexidade, acerca da cognição como um processo geral da vida em todos os níveis.

${ }^{8} \mathrm{O}$ que, entretanto, não se confunde com 
relativismo. Viveiros de Castro (2002: 129) sustenta que "[...] não se trata de afirmar a relatividade do verdadeiro, mas sim a verdade do relativo. É digno de nota que [Roy] Wagner associe a noção de relação à de ponto de vista (os termos relacionados são pontos de vista), e que essa ideia de uma verdade do relativo defina justamente o que Deleuze chama de "perspectivismo". Pois o perspectivismo - o de Leibniz e Nietzsche como o dos Tukano ou Juruna — não é um relativismo, isto é, afirmação de uma relatividade do verdadeiro, mas um relacionalismo, pelo qual se afirma que $a$ verdade do relativo é a relação" [grifos no original]. Ver também Viveiros de Castro (2007).

${ }^{9}$ Tomamos aqui o conceito de equívoco de Viveiros de Castro (2004), que significa sucintamente o momento em que duas partes falam sobre um mesmo assunto e não percebem que definições conceituais são distintas para ambas. $\mathrm{O}$ autor mostra que sempre haverá algum equívoco na relação entre cosmologias distintas, mas que ele pode ser um "equivoco controlado" quando as partes percebem suas limitações conceituais.

${ }^{10}$ A noção de ontologia deve ao pensamento filosófico europeu sua história, mas aqui é entendida, tal como propõe Blaser (2009), com o sentido muito próximo de "mundo". No entanto, ela também demarca que tipos de coisas existem ou podem existir. Assim sendo, Blaser indica que ontologias são performatizadas, não são anteriores à existência humana e não-humana ou às práticas.

\section{REFERÊNCIAS}

AIDESEP. 2007. Carta Abierta al señor García. Lima: Aidesep, p. 1-2. Disponível on-line em: http://wwwaidesep.org.pe/editor/documentos/59.pdf. Acessado em 29-11-2009.

_.2009. Demandas principales de los pueblos indígenas de la Amazonía para el diálogo nacional con el gobierno peruano. Lima: Aidesep, p. 1. Disponível on-line em: http://www.aidesep.org.pe/editor/documentos/648.jpg. Acessado em 08-12- 2009.

Awanash Wajush, S. 2009. Que el gobierno no crea que vamos a retroceder: el paro continua (Entrevista concedida à María Elena Hidalgo), in La Amazonía Rebelde. Editado por H. Alimonda, R. Hoetmer \& D. Saavedra Celestino, p. 57. Buenos Aires: CLACSO.

Blaser, M. 2009. Political Ontology: Cultural Studies without 'Cultures'. Cultural Studies 23 (5): 873-896.

Colectivo Indígena. 2010. La Idea es Perseguirlos. Lima: Paz y Esperanza; Oxfam, p.124 (Fotocópia).

Comisión Especial.2009. Informe Especial de la Comisión Especial para Investigar y Analizar los Sucesos de Bagua. Lima: Congreso de la República, 104 p.

Comisión Multipartidaria Encargada de Estudiar y Recomendar la Solución a la Problemática Indígena. 2008. Informe sobre los Decretos Legislativos Vinculados a los Pueblos Indígenas Promulgados por el Poder Ejecutivo en Mérito a la Ley $n^{\circ}$ 29.157. Lima: Área de transcripciones del Congreso de la República, 97 p.

De La Cadena, M. 2010. Indigenous Cosmopolitics in the Andes: Conceptual Reflections Beyond "Politics". Cultural Anthropology 25(2): 334-370.

Damonte, G. 2007. Minería y política: la recreación de luchas campesinas en dos comunidades andinas, in Minería, Movimientos Sociales y Respuestas Campesinas: una Ecología Politica de Transformaciones Territoriales. Editado por A. Bebbington, pp. 117-162. Lima: Instituto de Estudios Peruanos e Centro Peruano de Estudios Sociales.

Escobar, A. 1999. Comunidades Negras de 
Colombia: en Defensa de Biodiversidad, Territorio y Cultura. Biodiversidad 22: 15-20. 2008. Territories of Difference: Place, Movements, Life, Redes. Durham: Duke University Press. García Pérez,A. 2007a. ElSíndrome del Perro Hortelano. ElComercio, Lima, p. a4, 28 out. 2007b. Receta para acabar con el perro delhortelano. ElComercio, Lima, p. a6, 25 nov. 2008. El perro del hortelano contra el pobre. El Comercio, Lima, p. a4, 02 mar.

2009. Presidente Alan García advierte a nativos: "Ya está bueno de protestas" (Entrevista concedida ao Portal de Notícias Peru.com). Peru.com, Lima, 05 jun. Disponível on-line em http://www.peru. com/noticias/portada20090605/37781/ Presidente-Alan-Garcia-advierte-a-nativos-Ya-esta-bueno-de-protestas. Acessado em 01-12-2009.

Goldman, M. 2008. Os Tambores do Antropólogo: Antropologia Pós-Social e Etnografia. PontoUrbe. Revista do Núcleo de Antropologia Urbana da USP 2(3.0). Disponível on-line em http://n-a-u.org/pontourbe03/Goldman.html. Acessado em 8-12-2009.

Goodwin, B. 2007. Nature's Due: Healing our Fragmented Culture. Edinburgh: Floris Books.

Gordon, C. 2006. Economia Selvagem: Ritual e Mercadoria entre os Índios Xikrin-Mebêngôkre. São Paulo: Editora Unesp, ISA/ Rio de Janeiro: NUTI.

Kirsch, S. 2001. Property Effects. Social Networks and Compensation Claims in Melanesia. Social Anthropology 9(2):147-163.

Latour, B. 1994. Jamais fomos Modernos. Rio de Janeiro: Ed. 34.

Law, J. 2004. After Method: Mess in Social Science Research. London: Routledge.

Manuin, S. 2009. No estamos contra la inversión, la necesitamos (Entrevista concedida à
Iñigo Maneiro Labayén). Somos. (Caderno Especial de El Comercio), Lima, p. 24-25, 20 jun.

Mignolo, W. 2005. The Idea of Latin America. Malden, MA/ Oxford: Blackwell.

OIT-Organização Internacional do Trabalho. 1989. Convenção $n^{\circ} 169$ sobre Povos Indígenas e Tribais (adotada em Genebra, em 27 de junho de 1989).

Pizango, A. 2009. Los Nativos no Son Manipulados y el Viaje de Simon Sería en Vano (Entrevista concedida à Rocío Maldonado). La Republica, Lima, p. 04, 24 maio.

Quijano, A. 1991. Colonialidad y Modernidad/Racionalidad. Peru Indigena 13:29(11-20).

Salas, G. 2004. Política distrital, propietarios individuales e institucionalidad comunal: $\mathrm{La}$ administración de los fondos de la venta de tierras al Proyecto Antamina (San Marcos, Huari, Ancash), in En Perú: el problema agrario en debate, pp. 385-424. Editado por F. Eguren, M. I. Remy, e P.Oliart. Lima: Sepia.

Santos, B. de S. 2008. A gramática do tempo: para uma nova cultura política. Coleção para um novo senso comum v. $4.2^{\mathrm{a}}$ ed. São Paulo: Cortez.

Strathern, M. 2004. Partial connections. Walnut Creek: AltaMira Press.

.2006a. O gênero da dádiva: problemas com as mulheres e problemas com a sociedade na Melanésia. Campinas: Ed. da Unicamp.

2006b. Cutting the network, in $A n$ thropology in theory: issues in epistemology, pp. 480-491. Editado por H. Moore e T. Sanders. Oxford: Blackwell Publishing.

Tsing, A.L. 2005. Friction: an ethnography of global connection. Princeton: Princeton University Press.

Varela, F. 1999. Ethical know-how: action, wisdom and cognition. Stanford: Stanford University Press. 
Viveiros de Castro, E. Perspectival anthropology and the method of controlled equivocation. Tipiti - Journal of the Association for the Anthropology of Lowland South America 2(2): 1-16.

2002. O nativo relativo. Mana 8(1): 113-148.

2007. Filiação intensiva e aliança demoníaca. Novos Estudos Cebrap 77: 91-126.

Zapata, D. Sólo quieren llevarse todos nuestros recursos naturales (entrevista concedida à Johnattan Rupire y Mar Soler. Redacción, Lima, n. 104 e 105, 23 jun 2009. [Disponível on-line em: http:// www.politicaspublicas.net]. Acesso: 24 jun 2010.

Recebido em 10/07/2010.

Aprovado em 15/02/2011. 